\title{
OPTIMIZATION OF COPPER DISSOLUTION FROM ELECTRONIC WASTE PRINTED CIRCUIT BOARD USING LEACHING METHOD
}

\author{
Faradisa Athalla ${ }^{1)^{*}}$, Erni Sulistiawati ${ }^{2)}$ Iwan Setiawan $^{3)}$ \\ ${ }^{1)}$ Analisis Kimia, Sekolah Vokasi, Institut Pertanian Bogor, Jl. Kumbang No.14, \\ Babakan, Kecamatan Bogor Tengah, Kota Bogor, 16128, Indonesia; \\ 2) Sekolah Vokasi, Institut Pertanian Bogor, Jl. Kumbang No.14 Babakan,, Bogor, 16128, Indonesia; \\ ${ }^{3)}$ Pusat Penelitian Metalurgi dan Material, Kawasan PUSPIPTEK Gedung 470, Muncul, Setu, Muncul, \\ Kec. Setu, Kota Tangerang Selatan, 15314, Indonesia.
}

\section{ARTICLE INFO}

Article history:

Received 14 Jun 2021,

Revised 03 Jan 2022,

Accepted 16 Jan 2022

Available online 24 Jan 2022

$\begin{array}{cl}\text { Keywords: } \\ \qquad \quad \text { electronic } \\ \checkmark & \text { waste } \\ \checkmark & \text { PCB } \\ \checkmark & \text { dissolution } \\ \checkmark & \text { copper }\end{array}$

*corresponding author: faradisaathalla123@gmail.com Phone: +62895610427531

https://doi.org/10.31938/jsn.v $\underline{12 \mathrm{i} 1.322}$

\begin{abstract}
Electronic waste contains hazardous materials which have an adverse impact on the environment. Therefore, a solution is needed to recycle electronic waste. One solution is recovering copper metal from the Printed Circuit Board $(P C B)$ in electronic waste. The dissolution of copper is carried out by the leaching method, which means dissolving copper using a selective solvent. Analysis of copper was performed using Inductively Coupled Plasma-Optical Emission Spectroscopy (ICP-OES). This experiment aims to determine the factors that influence the optimization of copper dissolution from PCB electronic waste by leaching method and analysis the copper content using ICP-OES. The primary data obtained is the per cent recovery of each factor that affects copper dissolution, which is the concentration of sulfuric acid as a solvent, the percentage of solid / liquid, the speed of stirring, the temperature, and the length of stirring. The optimum conditions were achieved in the form of the highest recovery in each variation, which is $9.8 \%$ sulfuric acid, 5\% solid/liquid percentage, $200 \mathrm{rpm}$ stirring speed, and at temperature $60{ }^{\circ} \mathrm{C}$ with a stirring time of 120 minutes, the per cent recovery was obtained respectively $79.83 \%$; $74.86 \%$; $76.52 \%$; and $54.84 \%$.
\end{abstract}

\section{ABSTRAK \\ Optimalisasi Pelarutan Tembaga dari Limbah Elektronik Printed Circuit Board dengan Metode Leaching}

Limbah elektronik mengandung bahan-bahan berbahaya yang berdampak buruk bag lingkungan. Oleh sebab itu, diperlukan solusi untuk mendaur ulang limbah elektronik salah satunya adalah pengambilan kembali atau recovery logam tembaga dari Printed Circuit Board (PCB) pada limbah elektronik. Pelarutan tembaga dilakukan dengan metode leaching, yaitu dengan melarutkan tembaga menggunakan pelarut yang selektif. Analisis terhadap kadar tembaga dilakukan menggunakan Inductively Coupled Plasma-Optical Emission Spectroscopy (ICP-OES). Percobaan ini bertujuan untuk mendapatkan faktorfaktor yang berpengaruh pada optimalisasi pelarutan tembaga dari limbah elektronik PCB dengan metode leaching dengan analisis terhadap kadar tembaga menggunakan ICP-OES. Data primer yang diperoleh adalah persen recovery dari setiap faktor-faktor yang memengaruhi pelarutan tembaga, yaitu konsentrasi asam sulfat sebagai pelarut, persentase solid/liquid, kecepatan pengadukan, suhu, dan lama pengadukan. Kondisi optimum yang dicapai berupa recovery tertinggi pada setiap variasi, yaitu pada $9,8 \%$ asam sulfat, persentase $5 \%$ solid/liquid, kecepatan pengadukan $200 \mathrm{rpm}$, dan suhu pada $60{ }^{\circ} \mathrm{C}$ dengan lama pengadukan 120 menit diperoleh persen recovery secara berturut-turut $79,83 \%$; $74,86 \% ; 76,52 \%$; dan $54,84 \%$.

Kata kunci : elektronik, limbah, PCB, pelarut, tembaga 


\section{PENDAHULUAN}

Produk elektronik di era modern ini terus berinovasi dan semakin canggih. Hal ini menyebabkan penjualannya di pasaran terus mengalami peningkatan setiap tahun. Namun, nyatanya inovasi produk elektronik yang dikembangkan saat ini bukanlah teknologi tahan lama, sehingga mendorong konsumen untuk mengganti barang elektroniknya dalam kurun waktu yang lebih cepat. Kekhawatiran pun timbul akan limbah elektronik yang disebabkan oleh industri ini (Sadah et al., 2015). Limbah elektronik merupakan barang-barang elektronik atau listrik yang tidak digunakan lagi dan siap digantikan dengan barang-barang baru yang lebih canggih dan berkualitas (Nahor, 2019). Data yang dirilis United Nations University Institute for the Advances Study of Sustainability (UNU-IAS) menyebut limbah elektronik dunia telah mencapai 41,8 juta ton pada tahun 2014 (Kaya, 2019). Sedangkan di Indonesia sendiri, tercatat sejak tahun 2009 hingga 2016 jumlah limbah elektronik terus meningkat mencapai 900.000 ton (Arthaya et al., 2018).

Melimpahnya jumlah limbah elektronik saat ini nyatanya masih kurang mendapat perhatian serius dari pemerintah Indonesia, karena hingga kini belum ada sistem pengumpulan dan pengangkutan limbah elektronik yang terarah (Wahyono, 2013). Limbah elektronik tidak dapat disamakan dengan limbah pada umumnya karena limbah elektronik mengandung 40\% logam diantaranya logamlogam berat (Riafinola et al., 2018). Apabila limbah elektronik dibuang ke tempat pembuangan sampah, limbah akan tercuci ketika hujan. Air hujan pada timbunan sampah (lindi) mengandung logam berat dan zat beracun lainnya dapat mencemari sumber daya tanah dan air. Selain itu, racun tersebut dapat pula merusak jaringan tubuh manusia bahkan menyebabkan berbagai penyakit berbahaya (Nahor, 2019). Oleh karena itu, diperlukan upaya pengolahan limbah elektronik, salah satunya adalah pengambilan kembali atau recovery logam tembaga dari komponen yang terdapat dalam limbah elektronik, yaitu Printed Circuit Board (PCB). PCB merupakan papan yang terbuat dari bahan komposit polimer yang digunakan untuk menempatkan alat-alat elektronik yang dirangkai menjadi suatu rangkaian elektronik yang terintegrasi. Kandungan terbesar dari suatu PCB adalah logam tembaga yaitu 30,57\% (Birloaga et al., 2013).
Tembaga memiliki beragam kegunaan baik dalam bentuk murni maupun paduan, yaitu sebagai bahan peralatan transportasi, bahan pembuatan koin, bahan pipa air, dan lain-lain (Sari, 2018). Oleh karena itu, daur ulang tembaga dapat menjadi solusi dari pemanfaatan limbah elektronik yang sudah tidak digunakan lagi. Salah satu metode yang efisien untuk recovery tembaga dari limbah elektronik adalah leaching. Leaching dilakukan dengan melarutkan tembaga dari limbah PCB ke suatu pelarut (leaching agent) (Yuliusman, 2016). Beberapa faktor yang memengaruhi pelarutan tembaga dari limbah PCB dengan metode leaching, yaitu konsentrasi asam sulfat sebagai pelarut, persentase solid/liquid, kecepatan pengadukan, suhu, dan lama pengadukan. Berdasarkan hal-hal tersebut percobaan ini melakukan variasi pada setiap faktor yang memengaruhi pelarutan tembaga untuk menentukan kondisi optimum dalam recovery tembaga dari limbah PCB. Analisis kadar tembaga dalam percobaan dilakukan menggunakan Inductively Coupled Plasma-Optical Emission Spectroscopy (ICP-OES) dikarenakan mampu menganalisis secara selektif.

\section{BAHAN DAN METODE}

\section{Bahan dan Alat}

Bahan-bahan yang digunakan, yaitu limbah $\mathrm{PCB}$, asam sulfat, aquademineral, larutan standar multielemen $1000 \mathrm{mg} / \mathrm{L}$, asam nitrat 1:1, dan kertas saring Whatman 42. Alat-alat yang digunakan, yaitu reaktor yang terbuat dari bahan gelas dengan kapasitas $1 \mathrm{~L}$, pemanas listrik, pengaduk listrik Flotation Tester-1000 Heiko Seisakusho, pengendali suhu, neraca analitik, gelas piala, kaca arloji, batang pengaduk, sudip, bulb, pipet volumetrik, pipet tetes, corong, labu takar, gelas ukur, botol semprot, Inductively Coupled Plasma-Optical Emission Spectroscopy (ICP-OES) Agilent 700, X-Ray Flourescence (XRF) S2 Puma Bruker, stopwatch, dan oven.

\section{Metode}

\section{Penentuan Kadar Air Limbah PCB}

Limbah PCB yang telah diperkecil ukurannya menggunakan palu ditentukan kadar airnya dengan cara cawan porselin ditimbang. Selanjutnya, cawan porselin dipanaskan di dalam oven pada suhu $105{ }^{\circ} \mathrm{C}$ selama 1 jam, didinginkan, kemudian ditimbang. Langkah ini 
diulangi hingga bobot cawan porselin yang diperoleh konstan. Sampel limbah PCB ditimbang ke dalam cawan tersebut kemudian dipanaskan ke dalam oven suhu $105{ }^{\circ} \mathrm{C}$ selama 1 jam, didinginkan, kemudian ditimbang. Langkah ini diulangi hingga diperoleh bobot yang konstan. Kadar air (\%) dapat dihitung menggunakan rumus sebagai berikut :

$$
\operatorname{Kadar} \operatorname{Air}(\%)=\frac{(A-B)}{A} \times 100 \%
$$

Keterangan :

A = Bobot sampel $(\mathrm{g})$

$\mathrm{B}=$ Bobot sampel kering $(\mathrm{g})$

\section{Pembuatan Larutan Standar Tembaga}

Pembuatan larutan standar tembaga dilakukan dengan cara sejumlah larutan standar multielemen $1000 \mathrm{mg} / \mathrm{L}$ dipipet kemudian dimasukkan ke dalam labu takar $100 \mathrm{~mL}$ yang telah berisi 3 tetes asam nitrat pekat 1:1 dan ditera menggunakan aquademineral untuk membuat deret standar tembaga 20, 40, 60, 80, dan 100 $\mathrm{mg} / \mathrm{L}$. Deret standar tersebut kemudian dianalisis kadar tembaga menggunakan ICP-OES.

\section{Pelarutan Tembaga Limbah PCB menggunakan Variasi Konsentrasi Asam Sulfat}

Limbah PCB ditimbang dalam reaktor gelas kemudian ditambahkan larutan asam sulfat konsentrasi 4,9\% dalam aquademineral sebanyak $500 \mathrm{~mL}$. Leaching dilakukan dengan cara memasukkan pengaduk listrik ke dalam reaktor dengan kecepatan pengadukan 100 putaran per menit (rpm) selama 1 jam pada suhu ruang. Setelah selesai, larutan disaring menggunakan saringan Whatman 42. Filtrat yang diperoleh dilakukan pengenceran dan ditera aquademineral setelah itu dianalisis kadar tembaga menggunakan ICP-OES. Hal yang sama dilakukan pada konsentrasi asam sulfat $0 \% ; 9,8 \%$; dan $14,7 \%$.

\section{Pelarutan Tembaga Limbah PCB menggunakan Variasi Persentase Solid/Liquid}

Limbah PCB ditimbang bervariasi dengan persentase solid/liquid 5\%; 10\%; dan 20\% kemudian ditambahkan larutan asam sulfat 14,7\% dalam aquademineral sebanyak $500 \mathrm{~mL}$. Leaching dilakukan dengan cara memasukkan pengaduk listrik ke dalam reaktor dengan kecepatan pengadukan $100 \mathrm{rpm}$ selama 1 jam pada suhu ruang. Setelah selesai, larutan disaring menggunakan saringan Whatman 42. Filtrat yang diperoleh dilakukan pengenceran dan ditera aquademineral setelah itu dianalisis kadar tembaga menggunakan ICP-OES.

\section{Pelarutan Tembaga Limbah PCB menggunakan Variasi Kecepatan Pengadukan}

Limbah PCB ditimbang 20\% solid/liquid kemudian ditambahkan larutan asam sulfat $14,7 \%$ dalam Aqua aquademineral sebanyak $500 \mathrm{~mL}$. Leaching dilakukan dengan cara memasukkan pengaduk listrik ke dalam reaktor dengan kecepatan pengadukan $100 \mathrm{rpm}$ selama 1 jam pada suhu ruang. Setelah selesai, larutan disaring menggunakan saringan Whatman 42. Filtrat yang diperoleh dilakukan pengenceran dan ditera aquademineral setelah itu dianalisis kadar tembaga menggunakan ICP-OES. Hal yang sama dilakukan pada kecepatan pengadukan 50; 200; dan $300 \mathrm{rpm}$.

\section{Pelarutan Tembaga Limbah PCB menggunakan Variasi Suhu dan Lama Pengadukan}

Larutan asam sulfat $14,7 \%$ dalam aquademineral sebanyak $500 \mathrm{~mL}$ dimasukkan kedalam reaktor dan suhu dinaikkan sampai 45 ${ }^{\circ} \mathrm{C}$. Setelah suhu tercapai, ditambahkan limbah PCB 20\% solid/liquid. Leaching dilakukan dengan cara memasukkan pengaduk listrik ke dalam reaktor dengan kecepatan pengadukan 300 rpm, pada rentang lama pengadukan $0 ; 15 ; 30 ; 60$; dan 120 menit dilakukan sampling larutan sebanyak $5 \mathrm{~mL}$. Larutan tersebut disaring menggunakan saringan Whatman 42. Filtrat yang diperoleh dilakukan pengenceran dan ditera aquademineral. Setelah itu, dianalisis kadar tembaga menggunakan ICP-OES. Hal yang sama dilakukan pada suhu $60{ }^{\circ} \mathrm{C}$ dan $70{ }^{\circ} \mathrm{C}$.

\section{HASIL DAN PEMBAHASAN}

Limbah Printed Circuit Board (PCB) yang digunakan sebagai bahan baku dalam percobaan ini diambil dari pabrik penghasil limbah elektronik di Cikarang. PCB mengandung sekitar $30 \%$ material logam, $40 \%$ resin berbahan dasar organik, dan $30 \%$ material kaca sebagai penguat resin organik (Hino et al., 2009). Bahan resin organik dan material kaca merupakan polimer yang digunakan sebagai tempat melekatnya logam. Limbah PCB tersebut pada awalnya 
dilakukan uji menggunakan X-Ray Flouresencene (XRF) untuk mengetahui komponen logam yang terkandung didalamnya yang dapat dilihat pada Tabel 1.

Sampel limbah PCB yang digunakan pada percobaan ini tidak dipanaskan suhu tinggi, karena pemanasan di atas titik leleh solder dapat melepaskan gas beracun, tinggi konsumsi energi, dan merusak beberapa komponen yang dapat digunakan kembali (Zhang et al., 2015). Preparasi sampel limbah PCB dilakukan dengan cara memperkecil ukuran sampel menggunakan palu untuk memperbesar luas permukaan agar lebih mudah berinteraksi dengan pelarut.

Aqua regia, sianida, dan asam sulfat merupakan pelarut yang umum digunakan untuk melarutkan logam. Aqua regia dan sianida memberikan hasil yang baik dalam melarutkan logam, namun zat-zat ini bersifat racun dan menimbulkan pencemaran lingkungan. Oleh karena itu, percobaan ini menggunakan asam sulfat sebagai pelarut karena ion sulfat memiliki afinitas tinggi untuk ion logam serta lebih ekonomis dari aqua regia dan sianida (Hossain et al., 2018). Selain itu, asam sulfat juga memiliki tingkat leaching (ekstraksi) tembaga yang tinggi, tingkat polusi lingkungan yang rendah, dan konsumsi energi yang rendah (Wang et al., 2019).

Pelarutan tembaga dari limbah PCB dengan asam sulfat menghasilkan warna biru pada larutannya. Warna biru tersebut diketahui sebagai larutan tembaga (II) sulfat (Vogel, 1979) dengan reaksi menurut Fitrony et al., (2013) sebagai berikut:

$$
\mathrm{Cu}+\mathrm{H}_{2} \mathrm{SO}_{4}+5 \mathrm{H}_{2} \mathrm{O} \rightarrow \mathrm{CuSO}_{4} \cdot 5 \mathrm{H}_{2} \mathrm{O}+\mathrm{H}_{2}
$$

Setelah proses pelarutan selesai, masih terdapat residu yang tidak larut sehingga dilakukan penyaringan menggunakan kertas saring Whatman 42. Filtrat tersebut kemudian dilakukan pengenceran agar dapat masuk pada rentang deret standar. Analisis dilakukan menggunakan ICP-OES dengan kurva deret standar tembaga terlihat pada Gambar 1. Berdasarkan Gambar 1, diketahui bahwa kurva deret standar tembaga memiliki persamaan garis $\mathrm{Y}=-73,6324+63,0495 \mathrm{X}$ dengan koefisien determinasi $\left(\mathrm{R}^{2}\right)$ 0,9985. Hal ini menunjukkan linearitas yang baik dikarenakan telah memenuhi persyaratan AOAC (2011) yaitu $\mathrm{R}^{2}>0,990$ sebagai keberterimaan dalam metode analisis. Linearitas menggambarkan kemampuan metode analisis memberikan respon proporsional terhadap konsentrasi analit dalam sampel (Pirdaus et al., 2018). Penggunaan variasi pada percobaan dilakukan untuk melihat pengaruhnya terhadap pelarutan tembaga dari limbah PCB.

Tabel 1 Hasil XRF limbah PCB kering

\begin{tabular}{cc}
\hline Unsur & Persen Fraksi (\%) \\
\hline $\mathrm{CuO}$ & 22,74 \\
$\mathrm{Fe}_{2} \mathrm{O}_{3}$ & 24,88 \\
$\mathrm{NiO}$ & 0,02 \\
Lainnya $\left(\mathrm{Cl}, \mathrm{Na}_{2} \mathrm{O}, \mathrm{MgO}, \mathrm{Al}_{2} \mathrm{O}_{3}, \mathrm{SiO}_{2}, \mathrm{P}_{2} \mathrm{O}_{5}, \mathrm{SO}_{3}, \mathrm{CaO}\right.$, & 52,36 \\
$\left.\mathrm{ZnO}, \mathrm{BaO}, \mathrm{MnO}_{2}, \mathrm{SrO}\right)$ & \\
\hline
\end{tabular}

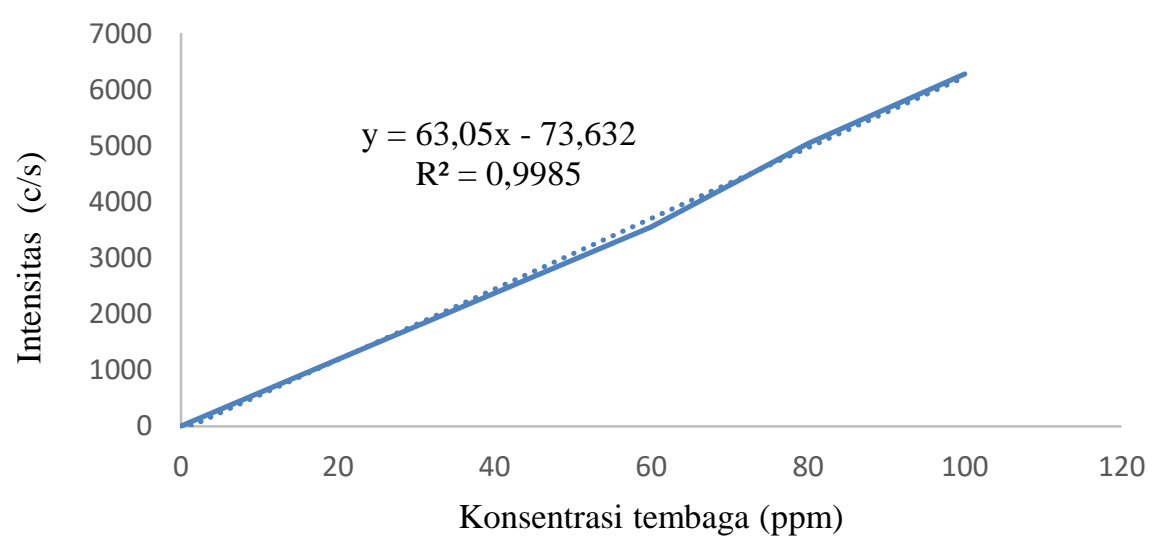

Gambar 1. Kurva deret standar tembaga 


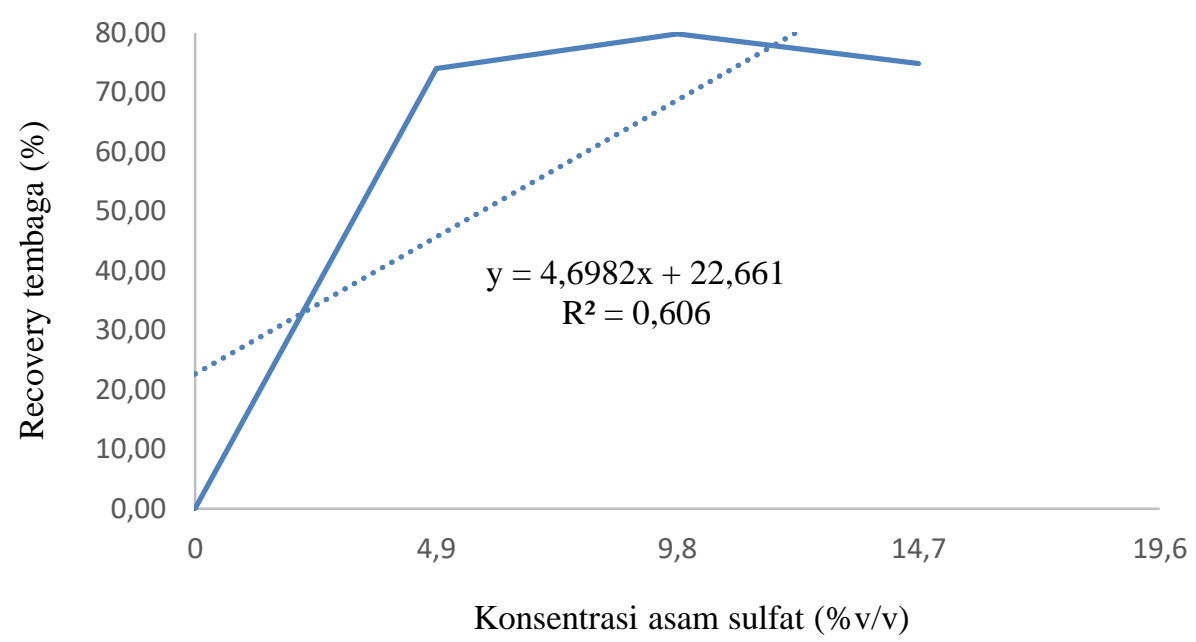

Gambar 2. Kurva antara recovery tembaga dengan konsentrasi asam sulfat

\section{Pengaruh Konsentrasi Asam Sulfat terhadap Pelarutan Tembaga}

Konsentrasi asam sulfat sebagai pelarut memainkan peran yang sangat penting yaitu aktivitas $\mathrm{H}^{+}$yang menghasilkan pelepasan ikatanikatan dalam limbah PCB untuk dapat melarutkan tembaga secara optimum. Percobaan ini memvariasikan beberapa konsentrasi asam sulfat, yaitu $0 \% ; 4,9 \%$; $9,8 \%$; dan $14,7 \%$ untuk melihat pengaruh dari besarnya konsentrasi asam sulfat terhadap kemampuannya dalam melarutkan tembaga dari limbah PCB dengan persentase solid/liquid 5\%, kecepatan pengadukan $100 \mathrm{rpm}$, dan dilakukan pada suhu ruang. Hasil yang diperoleh terlihat pada Gambar 2.

Pemilihan variasi konsentrasi tersebut berdasarkan percobaan yang dilakukan Royani et al. (2017), pada percobaan tersebut hasil yang diperoleh menunjukkan meningkatnya recovery logam dengan meningkatnya konsentrasi asam sulfat. Hal itu dikarenakan peningkatan konsentrasi asam sulfat dapat meningkatkan laju kecepatan reaksi dan laju difusi $\mathrm{H}^{+}$. Konsentrasi yang lebih tinggi dapat meningkatkan laju dari leaching, dikarenakan semakin tingginya konsentrasi pelarut akan meningkatkan luas permukaan kontak antara molekul solut dengan pelarut (Habashi, 1970). Berdasarkan Gambar 2, dapat diketahui bahwa ketika konsentrasi asam sulfat lebih dari 4,9\%, laju leaching tembaga tidak berubah secara signifikan. Hal ini karena peningkatkan konsentrasi asam sulfat dapat mendorong pelepasan ikatan-ikatan fase mineral dalam sampel dan membuat tembaga terekstrak dalam jumlah besar. Konsentrasi asam sulfat 9,8\% memiliki recovery tembaga tertinggi, namun terjadi penurunan recovery pada $14,7 \%$ kemungkinan karena kemampuan larutan asam sulfat untuk melarutkan tembaga telah jenuh sehingga penambahan konsentrasi lebih tinggi tidak lagi efektif (Ifa \& Nurjannah, 2017). Di samping itu, percobaan ini menggunakan sampel basah yang menyebabkan nisbah massa dari sampel dapat berubah dan memengaruhi jumlah tembaga yang akan larut.

\section{Pengaruh Solid Liquid Limbah PCB terhadap Pelarutan Tembaga}

Percobaan pelarutan tembaga menggunakan variasi solid/liquid dilakukan dengan pelarut asam sulfat konsentrasi $14,7 \%$. Variasi persentase solid/liquid yang dilakukan pada percobaan hanya pada $5 \%$; $10 \%$; dan $20 \%$ dimana hal tersebut belum memenuhi asas statistik, hal ini dikarenakan keterbatasan waktu percobaan dalam penyusunan karya ilmiah ini. Ketiga variasi persentase solid/liquid dilakukan dengan kecepatan pengadukan $100 \mathrm{rpm}$ pada suhu ruang. Hasil yang diperoleh terlihat pada Gambar 3.

Hasil tersebut menunjukkan bahwa persentase solid/liquid 5\% memiliki recovery tembaga tertinggi. Semakin tingginya persentase solid/liquid akan menurunkan jumlah tembaga yang akan larut. Hal ini disebabkan pada saat persentase solid/liquid bertambah maka jumlah limbah PCB pun bertambah dengan jumlah pelarut untuk leaching tetap sama yaitu $500 \mathrm{~mL}$. Kesempatan untuk bereaksi antara tembaga dengan larutan asam sulfat pun akan semakin kecil akibat mobilitas (gerakan) atom atau ion yang terbatas (Sarempa \& Isjudarto, 2019). Hal ini sesuai dengan pernyataan Habashi (1970), laju dari leaching akan semakin menurun bila persentase solid/liquid dinaikkan. 


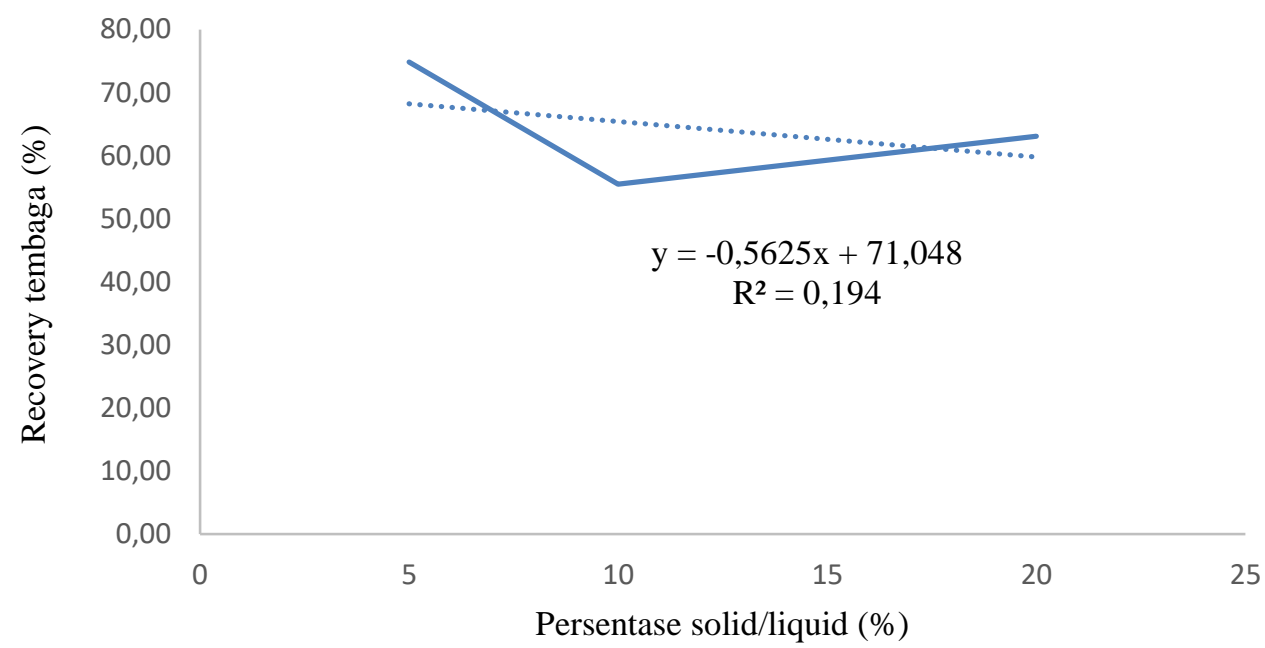

Gambar 3. Kurva antara recovery tembaga dengan persentase solid/liquid

Berdasarkan Gambar 3, diketahui bahwa persentase $20 \%$ solid/liquid mengalami peningkatan recovery tembaga, dimana seharusnya recovery semakin menurun. Hal ini terjadi akibat percobaan dilakukan pada suhu ruang yang memungkinkan pada $20 \%$ solid/liquid terjadi pada suhu yang lebih tinggi dari 10\% solid/liquid sehingga tembaga dapat larut lebih baik karena suhu yang lebih tinggi akan meningkatkan laju leaching. Percobaan selanjutnya menggunakan persentase solid/liquid $20 \%$ dikarenakan percobaan ini diperuntukkan untuk kapasitas industri yang akan menampung banyak limbah PCB dengan penggunaan asam sulfat yang ditekan jumlahnya agar tidak terlalu membutuhkan biaya besar.

Penggunaan pelarut asam sulfat $14,7 \%$ dipilih karena dalam percobaan ini mengacu pada hasil teoritis bahwa semakin tingginya konsentrasi asam sulfat akan meningkatkan recovery logam (Royani et al. 2017). Namun, hasil pada percobaan menunjukkan penurunan recovery tembaga pada variasi konsentrasi asam sulfat tertinggi tersebut. Keterbatasan waktu dalam percobaan membuat percobaan tidak dapat diulang kembali, kemungkinan hasil percobaan variasi solid/liquid akan lebih baik bila menggunaan konsentrasi asam sulfat optimum pada percobaan ini, yaitu $9,8 \%$.

\section{Pengaruh Kecepatan Pengadukan terhadap Pelarutan Tembaga}

Pelarutan tembaga dari limbah PCB selanjutnya dilakukan percobaan variasi kecepatan pengadukan pada proses leaching dalam reaktor dengan konsentrasi pelarut ditetapkan $14,7 \%$ asam sulfat, persentase solid/liquid $20 \%$, dan dilakukan pada suhu ruang. Variasi kecepatan pengadukan dilakukan pada 50; 100; 200; dan 300 rpm. Hasil yang diperoleh dapat dilihat pada Gambar 4.

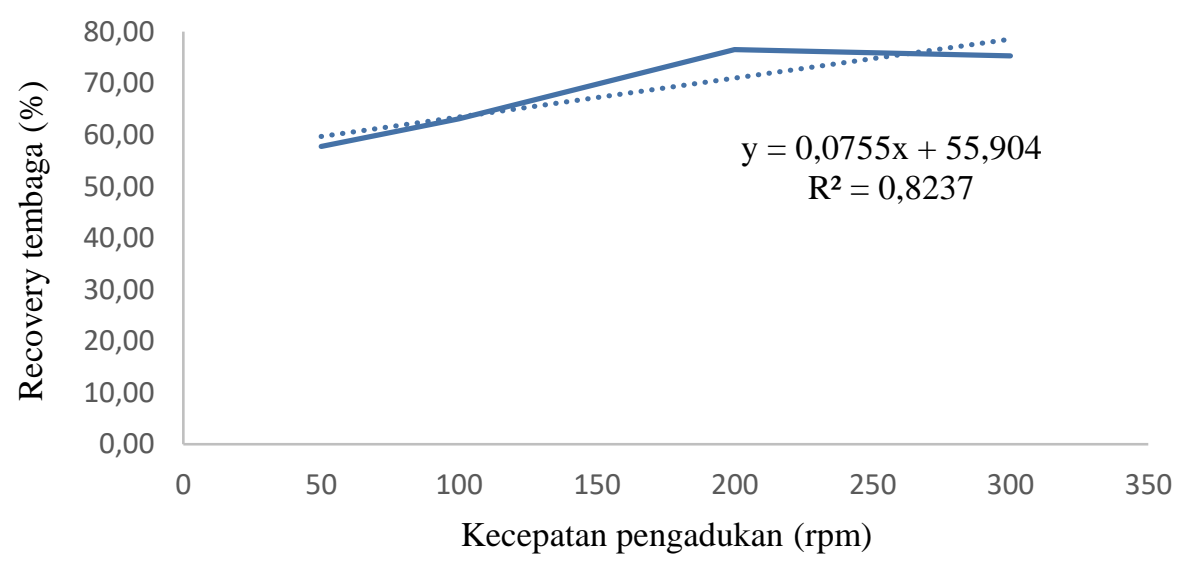

Gambar 4. Kurva antara recovery tembaga dengan kecepatan pengadukan 


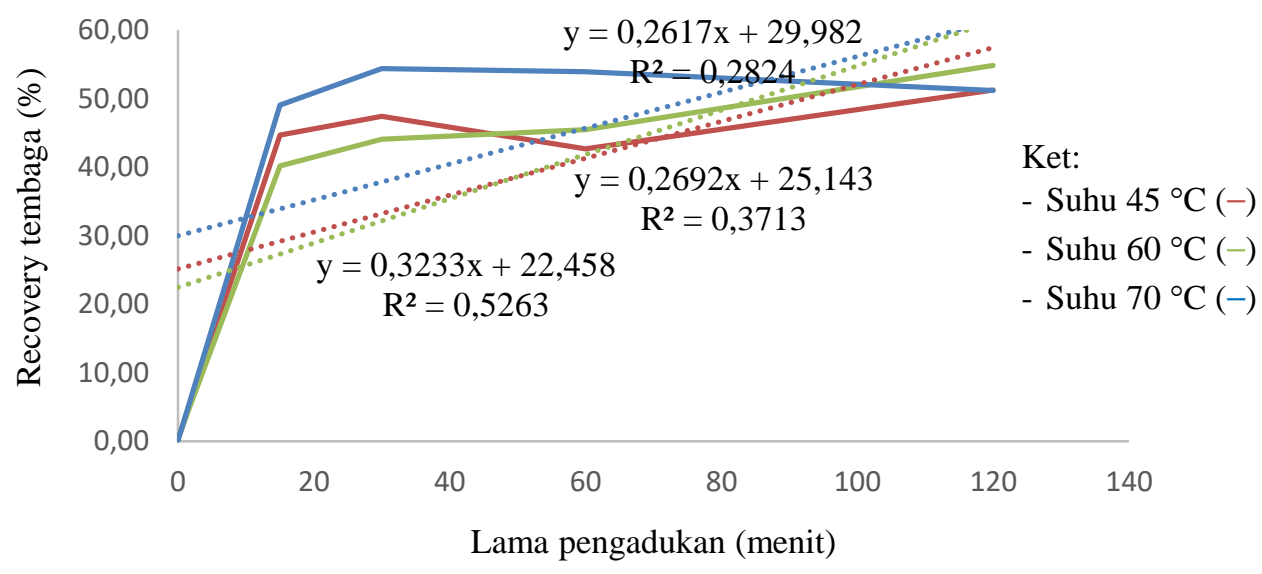

Gambar 5. Kurva antara recovery tembaga dengan lama pengadukan menggunakan variasi suhu

Variasi kecepatan pengadukan yang dipilih pada percobaan ini mengacu pada percobaan Royani et al. (2017), yaitu peningkatan recovery logam akan meningkat dengan meningkatnya kecepatan pengadukan. Pengadukan memberikan gaya mekanik yang baik untuk kontak antara padatan dan pelarut sehingga laju difusi meningkat (Prasetyo \& Yosephine, 2012). Selain itu, pengadukan dapat memengaruhi pelepasan elemen dengan meningkatkan difusi internal ke permukaan partikel yang tidak bereaksi. Peningkatan kecepatan pengadukan memungkinan sampel terurai dengan baik sehingga tingkat leaching meningkat (Ni'am et al., 2019). Berdasarkan Gambar 4, peningkatan kecepatan pengadukan dari $50 \mathrm{rpm}$ hingga 200 rpm sejalan dengan meningkatnya recovery tembaga. Kecepatan pengadukan 200 rpm memiliki recovery tembaga tertinggi. Namun ketika melebihi $200 \mathrm{rpm}$, difusi eksternal (difusi menuju lapisan batas) menjadi kecil dan difusi menjadi dikontrol difusi intenal (difusi menuju permukaan padatan) oleh karena itu tingkat leaching pada dasarnya tidak berubah (Shi et al., 2019).

\section{Pengaruh Suhu dan Lama Pengadukan terhadap Pelarutan Tembaga}

Pelarutan tembaga dari limbah PCB juga dipengaruhi oleh suhu dan lama pengadukan. Percobaan ini memvariasikan beberapa suhu untuk melihat pengaruh dari tinggi rendahnya suhu dengan lama pengadukan $0 ; 15 ; 30 ; 60$; dan 120 menit pada proses leaching terhadap kemampuannya dalam melarutkan tembaga dari limbah PCB dengan ditetapkan konsentrasi asam sulfat yang digunakan $14,7 \%$, persentase solid/liquid $20 \%$, dan kecepatan pengadukan 300 rpm. Hasil yang diperoleh dapat dilihat pada Gambar 5.

Berdasarkan percobaan yang telah dilakukan, diketahui recovery logam tembaga dari limbah PCB hanya memiliki nilai tertinggi sebesar $79,83 \%$. Hal ini kemungkinan karena keberadaan polimer yang melapisi tembaga dalam PCB. Menurut Bhavsar (2014), di dalam PCB selain terkandung tembaga terdapat material laminate. Laminate atau substrat digunakan untuk menahan lapisan-lapisan pada PCB yang terdiri dari komposit resin dan bahan penguat. Terdapat berbagai macam jenis substrat sesuai keperuntukannya dan jenis yang paling umum digunakan adalah FR-4. Jenis FR-4 memiliki sifat ketahanan beban yang baik, tahan terhadap api, dan ketika ada kenaikan suhu sifat mekanik, listrik, fisik material tetap terjaga. Standar dari FR-4 memiliki suhu dekomposisi tinggi yaitu lebih dari $345^{\circ} \mathrm{C}$ (Sunstone, 2020).

Resin berperan sebagai zat pengikat di dalam PCB. Jenis substrat FR-4 memiliki jenis resin, yaitu epoksi yang memiliki sifat ketahanan retak yang tinggi dan stabil pada suhu tinggi (Ellis $\&$ Smith, 2009). Fiberglass merupakan bahan penguat dalam papan PCB yang berfungsi untuk memperkuat matriks polimer (resin) untuk membentuk komposit. Sebagai penguat, fiberglass berkontribusi terutama listrik, termal, dan manfaat mekanis ke matriks polimer di sekitarnya. Fiberglass merupakan isolator yang sangat baik untuk PCB karena memiliki sifat dielektrik yang baik, memiliki stabilitas termal yang sangat baik, serta sensitivitas rendah terhadap kelembaban dan korosi kimia (Longobardo, 2009). Keberadaan dari polimer yang melapisi tembaga dalam PCB inilah yang kemungkinan menghambat proses difusi antara ion tembaga dengan pelarut asam sulfat 
dikarenakan dalam preparasi limbah PCB ini tidak dilakukan pemanasan suhu tinggi untuk mendekomposisi bahan-bahan tersebut sehingga pelarutan tembaga belum dapat maksimal.

\section{KESIMPULAN}

Kondisi optimum yang dicapai berupa recovery tertinggi pada setiap variasi pelarutan tembaga dari limbah elektronik Printed Circuit Board (PCB) dengan metode leaching dengan analisis terhadap kadar tembaga menggunakan Inductively Coupled Plasma-Optical Emission Spectroscopy (ICP-OES) diperoleh pada konsentrasi $9,8 \%$ asam sulfat yaitu sebesar $79,83 \%$, pada persentase solid/liquid $5 \%$ yaitu $74,86 \%$, kecepatan pengadukan $200 \mathrm{rpm}$ yaitu sebesar $76,52 \%$, serta suhu $60{ }^{\circ} \mathrm{C}$ dengan lama pengadukan 120 menit yaitu $54,84 \%$.

\section{UCAPAN TERIMA KASIH}

Penulis sampaikan terimakasih kepada Dr. drh. Erni Sulistiawati, SP1, APVet. selaku dosen pembimbing, Dr. Ir. Rudi Subagja, Januar Irawan, S.T., Bimo Sukma Wibawa, A.Md., dan Suyanto yang telah membantu selama pengumpulan data. Terima kasih pun penulis ucapkan pada Almarhumah Ibu, Ayah, serta seluruh pihak yang telah mendukung penelitian dan penulisan karya ilmiah ini.

\section{DAFTAR PUSTAKA}

Arthaya, B.M., Ariningsih, P.K, \& Haryani C. (2018). Peran konsep reverse logistic dalam perancangan penanganan baterai laptop bekas. J. Oto. Ktrl. Inst, 10(2), 97110.

Bhavsar, Shinde, N.R. \& Bhat M. (2014). Determination of mechanical properties of PCB. IJMER, 2(4), 2321-5747.

Birloaga, I., Michelis, I.D., Ferella, F., Buzatu, M. \& Veglio, F. (2013). Study on the influence of various factors in the hydrometallurgical processing of waste printed circuit boards for copper and gold recovery. Waste Manage, 33, 935-941.
Ellis, B. \& Smith, R. (2009). Polymer a Property Database. Boca Raton, US: Taylor \& Francis Group.

Fitrony, Fauzi, R., Qadariyah, L. \& Mahfud. (2013). Pembuatan kristal tembaga sulfat pentahidrat $\left(\mathrm{CuSO}_{4} \cdot 5 \mathrm{H}_{2} \mathrm{O}\right)$ dari tembaga bekas kumparan. Jurnal Teknik POMITS. 2(1), 121-125.

Habashi, F. (1970). Principles of Extractive Metallurgy Volume 2 Hydrometallurgy. London, UK: Gordon \& Breach.

Hino, T., Agawa, R., Moriya, Y., Nishida, M., Tsugita, Y. \& Araki, T. (2009). Techniques to kumseparate metal from waste printed circuit boards from discarded personal computers. Journal of Material Cycles and Waste Management. $11,42-54$.

Hossain, M.S., Yahaya, A.N.A. \& Yacob, L.S. (2018). Selective recovery of copper from waste mobile phone printed circuit boards using sulphuric acid leaching. Prosiding The 3rd International Conference on Green Chemical Engineering Technology; 2018. Materials Science. 21698-21702.

Ifa, L., Nurjannah, N. (2017). Ekstraksi vanadium pentaoksida $\left(\mathrm{V}_{2} \mathrm{O}_{5}\right)$ dari katalis bekas. Prosiding Seminar Nasional Teknologi IV; 2017 Nov 9; Samarinda. Samarinda: Fakultas Teknik - Universitas Mulawarman.

Kaya, M. (2019). Electronic Waste and Printed Circuit Board Recycling Technologies. Eskitehir, TR: Springer.

Longobardo, A.V. (2009). Glass fibers for printed circuit boards. Fiberglass and Glass Technology. 175-196.

Nahor, J.J. (2019). Implikasi dan pengelolaan limbah elektronik. Buletin Utama Teknik. 14(2), 116-119.

Ni'am, A.C., Wang, Y.F., Chen, S.W. \& You, S.J. (2019). Recovery of rare earth elements from waste permanent magnet (WPMs) via selective leaching using the taguchi method. Journal of the Taiwan Institute of Chemical Engineers. 97, 137-145.

Parubak, A.S., Sugiharto, E. \& Mudjiran, H. (2001). Pengaruh salinitas terhadap pelarutan tembaga $(\mathrm{Cu})$, timbal $(\mathrm{Pb})$, dan 
seng ( $\mathrm{Zn}$ ) dalam sampel tailing (pasir sisa). Indonesian Journal of Chemistry. $1(1), 16-22$.

Pirdaus, P., Rahman, M., Rinawati, Juliasih, N.L., Pratama, D., \& Kiswandono, A.A. (2018). Verifikasi metode analisis logam $\mathrm{Pb}, \mathrm{Cd}$, $\mathrm{Cr}, \mathrm{Cu}, \mathrm{Ni}, \mathrm{Co}, \mathrm{Fe}, \mathrm{Mn}$ dan Ba pada air menggunakan Inductively Coupled Plasma-Optical Emission Spectrometer (ICP-OES). Analit: Analytical and Environmental Chemistry. 3(1), 1-10.

Prasetyo, S. \& Yosephine, F. (2012). Model perpindahan massa pada ekstraksi saponin biji teh dengan pelarut isopropil alcohol 50\% dengan pengontakan secara disperse menggunakan analisis dimensi. Reaktor. 14(2), 87-94.

Riafinola, H., Lifitri, S., Ginting, M.T \& Budiana, B. (2018). Kajian efektivitas larutan etsa $\mathrm{NH}_{4} \mathrm{OH}, \quad \mathrm{FeCl}_{3}$, dan $\mathrm{CuCl}_{2}$ pada multilayar rigid printed circuit board. Journal of Applied Electrical Engineering. 3(1), 15-18.

Royani, A., Subagja, R., Manaf, A. (2017). Studi pelindian mangan secara reduksi dengan menggunakan larutan asam sulfat. Jurnal Riset Teknologi Industri. 11(1), 1-9.

Sadah, K., Syifaul, Fuada, S., \& Hidayati, N. (2015). Model baru dalam penanganan limbah elektronik di Indonesia berbasis integrasi seni. Prosiding SENTIA; 2015; Malang. Malang: Politeknik Negeri Malang. (7), 1-7.

Sarempa, A. \& Isjudarto, A. (2019). Optimasi recovery emas dan perak dengan sianidasi pada deposit bijih emas kadar rendah di PT. Nusa Halmahera Minerals Daerah Gosowong Kabupaten Halmahera Utara, Provinsi Maluku Utara. Dintek. 12(1), 19.

Shi, G., Liao, Y., Su, B., Zhang, Y., Wang, W. \& $\mathrm{Xi}$, J. (2019). Kinetics of copper extraction from copper smelting slag by pressure oxidative leaching with sulfuric acid. Journal Pre-proofs. Separation and Purification Technology. 1-17.

Sunstone. (2020). FR-4 PCB Materials. Sunstone Circuits [Internet]. Diperoleh dari https://www.sunstone.com/pcbmanufacturingcapabilities/detailedcapabilities/pcb-materials/fr-4-material

Vogel. (1979). Textbook of Macro and Semimicro Qualitative Inorganic Analysis. New York, US: Longman.

Wahyono, S. (2013). Kebijakan pengelolaan limbah elektronik dalam lingkup global dan lokal. Jurnal Teknologi Lingkungan. 14(1), 17-24

Wang, G.R., Liu, Y.Y., Tong, L.L., Jin, Z.N., Chen, G.B. \& Yang, H.Y. (2019). Effect of temperature on leaching behavior of copper minerals with different occurrence states in complex copper oxide ores. Trans. Nonferrous Met. Soc. 29, 2192-2201.

Wanta, K.C., Tanujaya, F.H., Susanti, R.F., Petrus, H.T., Perdana, I. \& Astuti, W. (2018). Studi kinetika proses atmospheric pressure acid leaching bijih laterit limonit menggunakan larutan asam nitrat konsentrasi rendah. Jurnal Rekayasa Proses. 12(2), 77-84.

Yuliusman. (2016). Pengambilan kembali logam $\mathrm{Li}$ dari limbah baterai Li-ION dengan teknologi leaching menggunakan asam sitrat. SENTRA. 1, 278-284.

Zhang, X., Guan, J., Guo, Y., Yan, X., Yuan, H., Xu, J., Guo, J., Zhou, Y., Su, R. \& Guo, Z. (2015). Selective desoldering separation of tin-lead alloy for dismantling of electronic components from printed circuit boards. ACS Sustain. Chem. Eng. 3, 1696-1700. 